\title{
EL DISEÑO INDUSTRIAL Y LA RADIO EN "BAQUELITAS Y OTROS PLÁSTICOS. LA COLECCIÓN RAFAEL ORTIZ”
}

\author{
INDUSTRIAL DESIGN AND RADIO IN "BAKELITES AND \\ OTHER PLASTICS. THE RAFAEL ORTIZ COLLECTION”
}

\author{
Luis F. Martínez-Montiel \\ Universidad de Sevilla. España \\ ORCID: 0000-0003-3454-1000 \\ 1mmmus@us.es
}

\begin{abstract}
"Baquelitas y otros plásticos. La Colección Rafael Ortiz", iniciada hace casi veinte años, ha ido avanzando a medida que su conocimiento se hacía mayor, porque para Rafael Ortiz coleccionar es una forma más de aprender. El tiempo y el aprendizaje sobre materiales, objetos y diseñadores le han afinado el ojo y han centrado su interés cada vez más. Lo que comenzó como un simple pasatiempo está en proceso de convertirse en una de las colecciones españolas más importantes de objetos de plástico. En este ensayo, la atención se centra en la colección de radios y en la evolución de los diseñadores industriales. Diseñadores, marcas y modelos de radio, que se mantienen en la colección, son analizados y valorados como parte del legado del siglo XX.

Palabras clave: diseño industrial; diseñadores industriales; radio; modernidad; siglo XX.
\end{abstract}

"Bakelites and other plastics. The Rafael Ortiz Collection", begun almost 20 years ago, has grown tentatively as his knowledge has increase, because for Rafael Ortiz collecting is another way of learning. Time and learning about materials, objects and designers, has fine his eye and focused his interest more and more. What began as a simple hobby is in process of becoming one of the most important Spanish collections of plastic objects. In this paper the focus is on radio collection and the evolution of industrial designers. Designers, brands and models kept on the collection are analyzed and valued as part of a legacy from $20^{\text {th }}$ century.

Keywords: industrial design; industrial designers; radio; modernity; $20^{\text {th }}$ century.

"Baquelitas y otros plásticos. La Colección Rafael Ortiz" es, sin lugar a duda, una de las más originales y extensas que se custodian en Sevilla y en su campo casi internacionalmente. Iniciada, como una afición, en los años centrales de la década de 1990, ha ido creciendo a la vez que el conocimiento de Rafael Ortiz sobre 
el material en el que se basa se iba desarrollando. El interés por la belleza que los objetos realizados en baquelita trasmitían fue el verdadero origen de su colección. Con el tiempo, variables de esta y otros plásticos, más evolucionados, como el plaskon o el catalín, han entrando a formar parte de ella. Poco a poco y con la paciencia de los grandes coleccionistas, Rafael Ortiz ha ido formando un interesante corpus que ha sido expuesto en diferentes muestras ${ }^{1}$. Las visitas a mercadillos españoles e internacionales le proporcionaron las piezas iniciales, aunque pronto se fueron sumando adquisiciones mucho más complejas, realizadas en subastas, cuando la definición de su colección se iba asentando. El tiempo y el aprendizaje sobre materiales, objetos y diseñadores le han ayudado a ir centrando sus intereses y a consolidar las líneas maestras de la misma. En estos momentos, la colección, siempre relacionada con los diferentes tipos de plásticos, se ha cualificado gracias a la búsqueda de las piezas más destacadas de los grandes diseñadores. Diseñadores en su mayor parte desconocidos para el gran público, pero enormemente reconocidos por los especialistas y cada vez más puestos en valor por las grandes instituciones. Aunque en la colección el repertorio de tipologías es muy amplio, destaca la sección de medios audiovisuales y, muy especialmente, por su calidad, belleza y rareza, el mundo de las radios, del que podría decirse que crece en paralelo con el avance de la profesión de diseñador industrial. En la actualidad, la colección conserva una treintena de radios entres las más de seiscientas piezas inventariadas ${ }^{2}$.

El papel de esta nueva disciplina fue fundamental sobre todo en los Estados Unidos, donde se hizo más patente la necesidad de cuidar las formas y con ello conseguir una mayor aceptación tanto del usuario final como de los fabricantes. No se debe olvidar que muchos de estos objetos, como es el caso de la radio, se empezaban a desarrollar en esos momentos y no había ejemplos anteriores, por lo que se trataba de encontrar formas que fueran fácilmente aceptables y que eliminaran las barreras para permitir su introducción masiva en los nuevos hogares. Además, el desarrollo del consumo en masa que propiciaron los objetos de plástico hizo emerger la figura del diseñador industrial. Tanto en el proceso creativo como en el resultado final, su papel se fue imponiendo, adoptando mayor relevancia incluso que la del propio artista del que en un principio se diferenciaba claramente. Con su participación cada vez más ineludible acabó influyendo directamente no solo en los procesos de fabricación sino también en su estructura

${ }^{1}$ En 2015 se celebró Baquelita. Creando futuro en el Museo Nacional de Artes Decorativas de Madrid, mientras que en 2018 se organizó la muestra Baquelita Paradise. El material que nos hizo modernos en el Espacio Santa Clara del Instituto de la Cultura y el Arte de Sevilla. Para ambas exposiciones se editaron catálogos donde se presenta gran parte de la colección. Martínez-Montiel, 2015; 2018.

${ }^{2}$ Cada una de las piezas de esta colección ha sido registrada con un número de inventario que se ha usado en el pie de las imágenes. 
y, con ello, en la forma y en el aspecto final del objeto. La creación de piezas con moldes potenció la sistematización del proceso productivo y la búsqueda de la facilidad en todas y cada una de las fases a las que este se encontraba sometido. La división de las tareas quedó rápidamente definida. El ingeniero se hacía cargo de los materiales y de supervisar la producción, mientras que el artista se encargaba de la apariencia final. Sin embargo, como ya se dijo, incluso en esta, la función del nuevo diseñador industrial acabaría marcando el resultado. La conformación de los moldes -el ingeniero realizaba el esqueleto de la pieza-repercutió igualmente en su apariencia formal. El artista se dedicaba a camuflarla al principio y, poco después, a reforzarla haciendo uso de las características que la estructura misma le ofrecía. De esta manera, se puede entender cómo el diseño industrial acabó marcando los parámetros básicos de estilos como el Decó de finales de los años veinte o las líneas aerodinámicas de lo que se conoce en diseño como el streamline de los años treinta ${ }^{3}$. Para Jeffrey Meikle, el diseño industrial surgió de una feliz conjunción de un mercado saturado que obligaba a los fabricantes a hacer sus productos fácilmente distinguibles y a un nuevo machine style que proporcionaba motivos fácilmente aplicables por los diseñadores y que eran reconocidos, por un público sensibilizado, como "moderno"4.

Surgió, de esta forma, en la Norteamérica de los años veinte, un grupo de profesionales del diseño industrial, que iniciaron lo que más adelante se llamó el "American way of life" y que dejaron con sus nuevas fórmulas improntas reconocibles en un amplio rango de objetos que abarcaron desde automóviles hasta aparatos de radios y otros pequeños electrodomésticos. Nombres como Walter Dorwin Teague, Raymond Loewy, Henry Dreyfuss o Norman Bel Geddes, todos ellos bien representados en la colección que se presenta, iniciaron la época dorada del diseño industrial estadounidense, convirtiéndose en claras referencias durante gran parte del siglo XX.

En la consolidación de esta nueva profesión, ocupó un lugar primordial la explosión de un pequeño electrodoméstico, poco conocido hasta los años veinte, la radio. Las nuevas posibilidades que la tecnología permitía facilitaban no solo la consecución de mejoras muy llamativas en el confort de los hogares sino también, como ya se ha dicho, la entrada en una nueva forma de vivir, de la que nuestra época es la heredera directa. Pese a que la radio hunde sus raíces en el siglo XIX, no fue hasta el primer cuarto del siglo pasado cuando realmente inicie su expansión y desarrollo total. En los primeros momentos, la radio era poco más que un extraño artilugio de cables, bobinas y metales que difícilmente atraía a un público general ${ }^{5}$. Es el periodo plenamente científico del invento, cuando solo se acercaban aquellos que tenían una curiosidad incontrolable. El artilugio se

\footnotetext{
${ }^{3}$ Martínez-Montiel, 2015: 13-14.

${ }^{4}$ Meikle, 1979: 39.

${ }^{5}$ Hawes, 1991: 7.
} 
acercaba más a la mesa de trabajo del Doctor Frankenstein que al sofisticado mueble, que con el tiempo llegó a ser.

Con el fin de la Primera Guerra Mundial y tras el avance tecnológico, que en buena medida ella ocasionó, la evolución se acelerará exponencialmente hasta el punto que ya en los años veinte se empieza a consolidar un primer tipo de mueble, el conocido como consola, que normalizó su uso. En Inglaterra, la radio fue el primer equipo eléctrico producido en masa. En 1922, cuando la radio comenzaba, existían 36.000 licencias para receptores, diez años después ya eran más de cuatro millones, pasando a más de nueve millones en 1939, lo que significaba que casi cada familia tenía acceso a una radio en su hogar ${ }^{6}$. Más parecido a una vitrina o a un aparador que a lo que hoy conocemos por radio, este nuevo mueble escondía en su interior el complejo entramado de cables necesarios para su todavía incipiente uso. La apuesta por entrar en los hogares llevó aparejada la necesidad de camuflarse en muebles ya aceptados por las familias. Los avances técnicos propiciaron una reducción en peso y en complejidad científica, lo cual facilitó su disminución física y la entrada progresiva en lo que se conoce como la edad de oro de la radio. Los aparatos eran cada vez menos ostentosos y más fáciles de transportar, dando paso a lo que se conoce como radio portátil, que tan decisiva fue en la evolución de las costumbres, modos y maneras de la vida contemporánea.

A todo ello ayudó, sin lugar a duda, un espíritu de modernidad que se había empezado a consolidar en la Exposition des Arts Décoratifs e Industriels Modernes de París en 1925. Hasta ese momento, en las ferias internacionales la mayoría de los objetos expuestos estaban basados en referentes históricos. En la de París, esto quedaba estrictamente prohibido hasta tal punto que en sus bases se estipulaba que los trabajos admitidos para la exposición debían mostrar una nueva inspiración y una originalidad contrastada. Las piezas podían ser presentadas por artistas, artesanos y fabricantes que hubiesen realizados modelos en los que se reflejara la modernidad. Las reproducciones, copias, imitaciones y falsificaciones quedaban estrictamente prohibidas, haciendo hincapié en la necesidad de adoptar el adjetivo moderno. La realidad fue algo distinta, pues mucho de los expositores seguían anclados en la tradición, sin embargo, se había comenzado a poner los cimientos para una nueva época ${ }^{7}$.

En "Baquelitas y otros plásticos. La Colección Rafael Ortiz" las radios conservadas son de este momento dorado, cuando ya el componente técnico se ha consolidado y ha dado paso a la reivindicación simbólica y estética por encima de la tecnológica. La apariencia de las radios se hace fundamental, pues los fabricantes ya no pueden competir entre sí por los avances técnicos, que cada poco y hasta ese momento se habían ido añadiendo, sino que lo hacen por la atracción estética de sus modelos, que permitía su incorporación en los hogares como parte

\footnotetext{
${ }^{6}$ Forty, 1995: 200.

7 Johnson, 2000: 9-10.
} 
del mobiliario. Asimismo, los avances en el tratamiento de los nuevos materiales permitían a los diseñadores realizar aquello que pensaban sin ningún límite creativo. Por primera vez se tiene la capacidad de ofrecer soluciones soñadas a los problemas funcionales y estéticos ${ }^{8}$. En la colección, cada una de las piezas han sido elegidas por su significación tanto por los avances que significaron como por la trascendencia de sus creadores.

Especialmente destacadas son las radios del fabricante británico EKCO, quien, a principios de los años treinta, buscando los aspectos innovadores y estéticos, fue capaz de dejar a un lado los voluminosos artefactos que hasta ese momento alojaban las radios para dar paso a una propuesta que fue fundamental con el paso del tiempo. A principios de 1930, W. S. Verrells y Eric C. Cole, directores de la EKCO, construyeron la primera gran planta de moldeados de plásticos de Gran Bretaña en su fábrica de Southend-on-Sea. El elevado coste del proceso de fabricación de los moldes les obligaba a no arriesgarse en los encargos de diseño, por lo que decidieron realizar un concurso para desarrollar una nueva propuesta de receptor para que albergara la nueva radio que estaban planteando. El premio lo ganó Wells Coates en 1932, quien creó el modelo $A-65$ que podemos observar en la colección (Figura 1 A).

Coates, arquitecto nacido en Japón en 1895 y educado inicialmente allí, estudió posteriormente en la Universidad McGill en Canadá, doctorándose en 1924 en la Universidad de Londres, desde donde trabajará para toda Europa y América. Además de sus obras de arquitectura moderna como los Lawn Roads Flats de Hampstead en Londres o Embassy Court en Brighton, realizó diseños de interiores para la $\mathrm{BBC}$, así como una amplia variedad de objetos industriales que van desde pianos hasta sus famosos calefactores ${ }^{9}$. La trascendencia que para Coates suponía la radio la dejó expresada en un texto para el Tottenham Sentinel de 1934. En el escribía: "un aparato de radio nunca debería ser disfrazado como algo más. Este tiene su propia función en la casa y es en muchos casos una posesión considerada más como el equivalente interior del coche en el exterior que un mueble cualquiera" ${ }^{10}$. En su diseño ganador para EKCO, Coates utilizó una forma circular que compaginaba el uso funcional de su creación, por su adecuación a la forma del altavoz, a la vez que evitaba las esquinas, con los fines estéticos del material. La simplicidad del diseño reducía además el número de herramientas necesarias para su realización, lo cual evidentemente rebajaba los costes de producción. Sin lugar a duda, el modelo se convirtió en uno de los más populares en el Reino Unido durante los años treinta. Su trabajo para la marca, de 1934 a 1937, se consolidó con nuevos encargos, entre ellos un desarrollo del mismo

\footnotetext{
${ }^{8}$ Silverstone/Haddon, 1996: 44-74.

${ }^{9}$ Museum of Modern Art, 1937: 95-96.

10 Tottenham Sentinel, 4-10-1934, recogido en Cohn, 1979: 30.
} 
modelo que finalmente fue comercializado como $A-76$, del que también se conserva un ejemplar en la colección sevillana ${ }^{11}$ (Figura $1 \mathrm{~B}$ ).

El primero de los modelos conservados responde a su variable resuelta en baquelita marrón imitando a madera, aunque también se realizaron en color negro, verde y marfil. En ambos modelos la caja circular se apoya en dos pies que se prolongan por el grosor de esta. En el primer ejemplo, el altavoz, protegido por una rejilla textil, se remarca por tres varillas metálicas. Es un claro ejemplo del uso conjunto de diferentes materiales que iban a proporcionar un mayor interés estético. Madera, metal, cristal y plástico se combinaban para conseguir los modelos más atractivos. En el segundo modelo, las varillas se desarrollaban horizontalmente ante el altavoz, mientras que en la mitad superior, con forma semicircular, se desarrollaba el dial. Todo el frontal quedaba completado con los tres botones para seleccionar la banda, la emisora y el volumen. La importancia del modelo se comprueba por su existencia en los principales museos internacionales o la inclusión en relevantes exposiciones, como la titulada The wireless show!, celebrada en el Victoria \& Albert Museum, en la cual ocupaba la portada del catálogo. Especialmente sugerente son los conservados en el MoMA y el Cooper Hewitt Design Museum, ambos en Nueva York, y en el Victoria \& Albert Museum de Londres ${ }^{12}$.

El fabricante había comprendido, con el éxito del modelo, que el buen diseño estaba unido a los buenos negocios, por lo que pronto comisionó a otro de los jóvenes arquitectos, Serge Chermayeff, para que diseñara otra de sus radios. El primero, realizado en baquelita, fue el modelo $A C 74$, del que existe uno en la colección de Rafael Ortiz, fechado en 1934 (Figura 1 A). Chermayeff, nacido en 1900 en Grozny (Chechenia) y descendiente de judíos españoles, murió en Wellfleet (Massachusetts) en 1996 como uno de los últimos representantes de la arquitectura moderna del siglo $\mathrm{XX}^{13}$. Arquitecto y pensador, sobre todo en sus últimos años, realizó también notables diseños de interiores. Sus modelos de radios, anteriores a su gran creación, el De La Warr Pavillion en Baxhill-on-sea (Sussex), ya muestran su concepto arquitectónico ${ }^{14}$. Su caja cuadrada, con las esquinas levemente suavizadas y su altavoz circular, sus huecos para los diales de sintonización y bandas, junto a los botones de volumen y selección nos ofrecen una primera aproximación a la arquitectura moderna del que sería un claro referente.

${ }^{11}$ Hafiz Elgohary, 1966: 190-199. http://discovery.ucl.ac.uk/1317970/1/309103.pdf (29-9-2019).

12 MoMA: https://www.moma.org/collection/works/185452?classifications $=3 \& \mathrm{~d}$ ate_begin $=$ Pre- $1850 \&$ date_end $=2018 \&$ locale $=$ es $\&$ page $=1 \& q=$ Wells + Coates $\&$ with images $=1$. Cooper Hewitt Smithsonian Design Museum: https://www.cooperhewitt. org/2019/04/17/radio-in-the-round/. Victoria \& Albert Museum: https://collections.vam. ac.uk/item/O22790/ekco-ad-65-radio-coates-wells-obe/ (29-9-2019).

${ }_{13}$ Museum of Modern Art, 1937: 95.

14 Powers, 1996. Hitchcock/Bauer, 1937: 8. 
Su pureza de líneas, su carencia de adornos y su diseño geométrico realzaban sus principales componentes y otorgaban una especial viveza a las piezas.

Tanto Coates como Chermayeff tuvieron un rápido reconocimiento con la creación de sus modelos para EKCO siendo incorporados en una de las primeras muestras en las que el diseño entraba abiertamente en los museos. La exposición titulada Design for use fue celebrada en el Museum of Modern Art de Nueva York en 1937, apenas unos años después de la creación de sus primeras radios. En ella se dejaban patentes algunas de las perspectivas más innovadoras del momento, haciendo alusión a tres principios básicos que revolucionaron los objetos primordiales de la vida cotidiana. Los factores que se resaltaron fueron la evolución tecnológica, que permitió el desarrollo de los métodos de producción; la propia revolución de la tecnología, que permitía la introducción de nuevos principios en el trabajo y el uso de nuevas materias primas; y la apertura a un diseño más orgánico y ergonómico, que permitía la integración en los objetos de la función, la tecnología y la forma ${ }^{15}$.

Otra de las piezas europeas de la colección es la sobresaliente Phonola modelo 547, diseñada por los hermanos Livio y Pier Castiglioni y por el también italiano Luigi Caccia Dominioni ${ }^{16}$. En Italia, durante casi toda la primera mitad del siglo, se fabricaron muy pocos receptores de radio, debido a la recesión financiera del país. La mayoría de estas fueron construidas en madera, aunque, como en el caso que nos ocupa, algunas fueron moldeadas en baquelita, material que de alguna forma daría comienzo al gran desarrollo del diseño italiano ${ }^{17}$. La Phonola, además, se escapaba de los tradicionales cánones ya establecidos para los receptores de radio, avanzando notablemente en la estética de la tipología (Figura 2). Fabricada en baquelita marrón y negra, se comercializó además un modelo en verde que es muy solicitado en la actualidad. Entre las características más notables del modelo estaba la posibilidad que ofrecía para ser apoyada en plano sobre su base o bien ser colgada en un muro. El elemento fundamental es su altavoz circular que sobresale inclinado hacia delante y su panel selector bajo el que se ubican los diversos botones de sintonía y volumen. Su forma recuerda claramente, aunque en mayor tamaño, las de los famosos teléfonos de baquelita con un aire futurista y una sobriedad y simplicidad que en alguna forma evoca los instrumentos militares de la época.

La importancia de la máquina era cada vez mayor en la vida cotidiana, sobre todo en un país como los Estados Unidos que había hecho decir a Oscar Wilde en 1883 que no había un país en el mundo con máquinas tan bellas como las de allí, donde belleza y fuerza se hacían una ${ }^{18}$. Las diferentes actitudes hacia las máquinas fueron evolucionando con la entrada del siglo XX donde, según Richard

\footnotetext{
${ }^{15}$ MoMA, 1937: 8.

16 Castiglioni, 2007.

17 Kingsley, 1999: 48.

18 Kowenhoven, 1967: 173.
} 
Wilson, se podían observar dos actitudes básicas, la exaltación o el rechazo. Estas se habían polarizado en las décadas de 1920 y 1930, donde el rechazo se caracterizaba por el deseo de disfrazarlas, mientras que los que la exaltaban reconocían la primacía de la máquina y luchaban por convertirlas en arte ${ }^{19}$.

Hasta ahora, aunque hemos hablado de la figura del diseñador industrial, las radios presentadas fueron diseñadas por arquitectos que habían visto las enormes posibilidades que les abría ese mundo. El paso a la figura del diseñador industrial estuvo especialmente ligado a la toma de conciencia de la carencia de un arte propio en los Estados Unidos y a la posibilidad de abanderar una nueva sensibilidad. Desde 1929, en que los arquitectos seguían copando la mayoría de las creaciones modernas, hasta 1934, el diseñador industrial fue consolidándose como una profesión lo suficientemente reconocida como para disputar los encargos a los principales arquitectos. Es el momento de la consolidación de los grandes estudios de diseño. Loewy, Dorwin Teague, Geddes, Dreyfuss, Vassos o Budlong empezaron a ser vistos como los grandes referentes de la modernidad en los Estados Unidos y todos ellos trabajaron para los fabricantes de radios más importantes del país. Cada uno en su medida contribuyó a crear el American way of life y, por expansión, su influencia en el del resto del mundo. El diseño industrial ocupó un papel básico en el desarrollo del sueño americano, así como alimentó los aspectos económicos consolidando lo que podríamos denominar "la vida moderna".

Raymond Loewy se convirtió en uno de los personajes más influyentes en la economía mundial a mitad del siglo XX. Su empresa, con cientos de trabajadores, se había establecido en los principales centros de poder. Desde Nueva York, Chicago, París o Londres, su estudio diseñaba toda clase de objetos, desde barras de labios hasta locomotoras, pasando obviamente por los receptores de radio. Fabricantes como la Pennsylvania Rail Road, Studebaker, Shell o Coca Cola eran sus clientes habituales, con lo que sus diseños afectaban a cientos de usuarios y los convertían en determinantes para los cambios económicos, culturales y estéticos de toda una época. Loewy, que había nacido en París y emigrado a Estados Unidos, dio sus primeros pasos como ilustrador comercial para revistas como Vogue, Harper Bazaar o Vanity Fair, aunque pronto se acercó al mundo del diseño industrial. Para él, como explica en su autobiografía, los productos norteamericanos eran fantásticos en producción y funcionalidad, aunque innecesaria e insoportablemente feos, ruidosos, malolientes y casi ofensivos ${ }^{20}$. Su estudio tenía en cuenta no solo la apariencia sino también la eficiencia de su fabricación, la calidad y durabilidad de los nuevos materiales, así como la facilidad y seguridad en su uso ${ }^{21}$.

Estos grandes diseñadores norteamericanos y sus obras son objetivos fundamentales en "Baquelitas y otros plásticos. La Colección Rafael Ortiz", donde

\footnotetext{
19 Wilson, 1986: 44-45.

${ }^{20}$ Loewy, 2002.

${ }^{21}$ Porter, 2002: XV-XVII.
} 
se encuentran algunas de las radios norteamericanas más características del momento. Entre ellas destacan dos ejemplares, uno en baquelita marrón y otro en marfil, del modelo realizado por Loewy para la Colonial Radio Corporation, conocido como New World Globe $700^{22}$ (Figura 3 B). El diseño fue presentado a la oficina estadounidense de patentes, quedando registrado en 1933, y en él se explicitaba su peculiar forma de esfera terrestre. Sobre un pedestal de planta hexagonal, donde se ubicaba el altavoz, se apoyaba el vástago, soporte del eje para el globo que aparecía ligeramente inclinado. En el ecuador de este, realizado en metal dorado, se incorporaban los selectores de banda, que aparecía en un rectángulo abierto en la esfera, y el del volumen. En la superficie se desarrollaba el dibujo de los continentes y mares. Más tarde, en 1938, fue patentada la construcción y disposición mecánica del interior del receptor realizadas por los también ingenieros Fulton Cutting y Howard A. Gates ${ }^{23}$. En el modelo, Loewy mezclaba la ingeniería con la estética apostando siempre por la simplicidad, la funcionalidad y la belleza. Una década después, cuando Loewy realiza la Radio Moderne 511 para la Emerson Radio and Phonograph Corp., también existente en la colección sevillana, la simplicidad ya es absoluta. Un receptor muy escueto con una base rectangular, en cuyo extremo derecho se ubican los selectores de banda y sonido, y sobre la que se desarrolla el dial y los altavoces, refuerza el concepto de funcionalidad y portabilidad, que los nuevos materiales plásticos, en este caso el conocido como plaskon, permitían. En el modelo se hacía patente el principio básico del diseño industrial que Loewy entendía comprometido con "la responsabilidad social de contribuir a la reducción del costo de los bienes manufacturados" y al crecimiento económico (Figura 3 A). Esto aceleraba el empleo y aportaba productos esenciales a las clases desfavorecidas. Para él eso era "democracia en acción" 24 .

La falta de precedentes para la elección de las formas de las radios conllevó, como se ha visto en los modelos de Loewy, la utilización de todo tipo de referentes como carcasas. Desde los vistos globos terráqueos, hasta barriles, pelotas de béisbol u otros, menos afortunados, fueron adaptados para recibir los componentes electrónicos. El enfoque conservador, con receptores en forma de muebles

${ }^{22}$ La marca Bakelite, que se publicitaba como el material de los mil usos, hizo una gran campaña de esta radio porque la entendió como una forma de popularizar el uso del material. Véase al respecto los anuncios publicados en la revista Electronics en febrero de 1934.

${ }^{23}$ Las patentes se encuentran archivadas en la Oficina de Patentes de Estados Unidos con fecha 24 de junio de 1933, siendo aceptada el 29 de agosto del mismo año con la numeración de patente 90.586 . La patente de la construcción mecánica fue presentada el 13 de marzo de 1934 siendo aprobada con número de patente 2.138 .959 el 6 de diciembre de 1938 .

${ }^{24}$ Porter, 2002: XX. 
tradicionales, dio paso a las verdaderas novedades. Con el paso del tiempo y su incorporación paulatina al mobiliario del hogar, la radio empezó a adoptar diseños auténticamente futuristas. En esa transformación, John Vassos fue uno de los grandes pioneros. Rechazaba la forma vertical que usaban las radios realizadas en madera, las llamadas "Catedrales", y apostaba por modelos realizados en nuevos materiales que acabaran con lo que denominaba "las monstruosidades que ahora padecemos" 25 . A ello acompañó que el desarrollo técnico llegó al límite, por lo que la única posibilidad de competencia entre fabricantes quedaba reducida a las innovaciones en el diseño de los receptores.

Especial significado en ese sentido fue el contrato de Vassos por la Radio Corporation of America (RCA), una de las principales distribuidoras de radios creada en 1919. Su mascota, el famoso perrito Nipper, es aún uno de los grandes iconos de la contemporaneidad ${ }^{26}$. Vassos pronto recomendó el uso de receptores más livianos y portátiles, aclarando que se estaba perdiendo la posibilidad de trabajar con materiales sintéticos como la baquelita, la formica o cualquier otro componente ligero al que podría acompañar el uso de metales para conseguir conjuntos más armoniosos y estéticos. Sus diseños de radios le proporcionaron gran fama, destacando entre ellos la serie $R C A$ Victor $96 X$, del que la colección Rafael Ortiz posee un extraordinario ejemplo. Fabricado en 1939 en baquelita azul y blanca, presenta una línea aerodinámica difícilmente alcanzable en los modelos realizados en madera (Figura 4). Las formas geométricas de formas redondeadas y rigurosas líneas verticales y horizontales le confieren un aspecto de gran modernidad y claras relaciones con la arquitectura más vanguardista del momento.

Junto a los diseñadores citados se puede situar a otro de los grandes nombres del diseño industrial, Norman Bel Geddes. Como los anteriores, y una vez superada la corriente del diseño como solucionador de problemas, Geddes puede considerarse como uno de los abanderados del embellecimiento de los objetos. Esa plusvalía estética, como la llaman Rispoli y Jordana, acabará imponiéndose a fines de los años treinta en Estados Unidos gracias a los pioneros que ahora estudiamos en relación con la fabricación de radios. En "esa lógica del capitalismo tardío la estética se había convertido en un potente mecanismo de inducción al consumo y, por lo tanto, en otro nuevo terreno de competencia feroz para el mundo empresarial" que enfrentó a los grandes diseñadores ${ }^{27}$. Geddes, que había iniciado su carrera como diseñador de escenarios para teatro, acabó siendo uno de los grandes nombres en la evolución de las formas de vidas americana. Su estudio desarrolló propuestas para las grandes ferias internacionales celebradas

${ }^{25}$ Shapiro, 2016: 81.

${ }^{26}$ El perro sentado ante el altavoz del fonógrafo y el lema "his master's voice" todavía perdura en el imaginario moderno. Al respecto véase Bunis, 1997: 169.

${ }^{27}$ Rispoli/Jordana, 2016: 421-422. 
en los Norteamérica durante los años treinta, que tendrán gran influencia en la modificación de los hábitos domésticos ${ }^{28}$. En ese sentido, el modelo realizado para Emerson, el FC400, será uno de los grandes éxitos de la definitiva implantación de la radio en los hogares. Este, del que existen dos ejemplares en la colección sevillana, se fabricó con dos acabados. El primero, denominado Patriot, fue realizado en catalín, uno de los nuevos plásticos desarrollados a partir de la baquelita, que permitía acabarlo en los colores rojo, blanco y azul de la bandera norteamericana, mientras que el segundo, igualmente realizado en catalín y publicitado como Aristocrat, presentaba un acabado que imitaba el carey. Desde su creación el modelo fue muy reconocido llegando a ser usado como imagen de uno de los sellos de la oficina postal editado en 2011 para conmemorar a los pioneros del diseño industrial en el país (Figura 5).

El último de los cuatro grandes, como en ocasiones han sido llamados, es Henry Dreyfuss, de quien la colección estudiada conserva uno de sus diseños de radio más aclamados, el modelo Sunburst $8 X$ 682, realizado para RCA Victor Corporation. Dreyfuss, quien podría ser considerado como el patrón del anticonsumismo -apenas cambió de hoteles o restaurantes cuando viajaba, permaneciendo fiel incluso al color de sus trajes-, es uno de los grandes desarrolladores de diseños de su época ${ }^{29}$. La radio asume esa simplicidad que el postulaba para su propia vida, un receptor casi rectangular con ángulos redondeados sobre una base moldurada como fórmula constructiva. En su centro, como único resalte, la circunferencia del altavoz y los botones, también circulares, aunque ubicados transversalmente, para sintonía y volumen. Esa pureza de línea y su esquematismo es el que le otorga la elegancia y belleza que lo hizo uno de los grandes modelos de radio del momento. En la colección estudiada se conserva un ejemplar de esta inventariada con el número 545 (Figura 6).

Al margen de estos grandes pioneros fueron apareciendo otra serie de diseñadores que contribuyeron al afianzamiento de la disciplina. Entre ellos, y para adecuarnos a las dimensiones del texto y a la importancia dentro de la colección que se estudia, se analizarán las piezas de Clarence Karstadt y de Robert Davol Budlong.

En la producción del primero, tiene especial importancia el modelo realizado para la Sears, Roebuck \& Co., dentro de la marca Silvertone ${ }^{30}$. Sears había abierto su sección de radios en los inicios de los años veinte incorporando pronto en su catálogo las modelos de tubos y baterías bajo la marca Silvertone. Sin embargo, el máximo desarrollo lo obtuvo en los años treinta cuando la radio, además de entretenimiento, proporcionaba información sobre las agresiones militares previas a la Segunda Guerra

${ }^{28}$ Szerlip, 2017. Maffei, 2018.

${ }^{29}$ Russell, 1997.

${ }^{30}$ Silvertone funcionó en asociación con Sears, Roebuck \& Co. desde 1915 hasta 1972. http://searsarchives.com/brands/silvertone.htm (22-10-2019). 
Mundial. Es en ese momento, 18 de noviembre de 1938, cuando Karstadt presentó en la oficina de patentes norteamericana un nuevo modelo de radio (Figura 7). La concesión definitiva de la patente para su fabricación la obtendría apenas unos meses después, el 24 de enero de 1939. Ese mismo año, el modelo se completaba con todo el desarrollo realizado por Alonson A. Scriven y Max B. Robbins ${ }^{31}$. Sears denominó el modelo como Silvertone "Rocket" Compact y fue publicitado como diseñado para "personas modernas que viven en un mundo moderno". Su precio de salida, 12,95 dólares, permitía elegir entre tres colores, marrón, negro, marfil. Ejemplares de estos dos últimos colores se encuentran en la colección sevillana, existiendo otros en las colecciones del Metropolitan Museum y del Brooklyn Museum, ambos en Nueva York.

La Silvertone turbine radio modelo 6110 presenta una forma cilíndrica situada en horizontal, que se inserta casi totalmente en un volumen rectangular resaltado con molduras horizontales, que ocultan el altavoz. En su extremo se sitúa el dial de sintonización. En la zona superior, se ubican seis botones para la selección de las estaciones preestablecidas, mientras que el volumen es controlado con un botón situado bajo el dial de sintonización. Formalmente el efecto que provoca es el de una máquina de gran tamaño y muy potente en pleno funcionamiento.

Por lo que se refiere a Robert Davol Budlong, la colección tiene quizás sus dos modelos más significativos, ambos para la marca Zenith: los conocidos como Pacemaker y Racetrack. El reconocimiento a la calidad de sus diseños lo obtuvo con la inclusión del primero de ellos en la exposición For modern living, comisariada por el arquitecto Alexander Girard para el Museum of Modern Art de Nueva York. Se destacaba en esta muestra que era la primera vez que este tipo de objetos eran presentados en el museo y que lo hacían en virtud de su excelente diseño. Aprovechaba la muestra las fechas en las que se presentaba, vacaciones de Navidad, para destacar que todos ellos eran factibles de ser adquiridos en las tiendas de la ciudad en ese mismo momento. Se exhibieron objetos de diferentes países y de diseñadores tan señalados como Isamu Noguchi, Eliot Noyes, Edith Heath, Alvar Aalto o Saul Steinberg, que compartieron en espacio con la radio de Budlong, que estaba a la venta por 22,95 dólares ${ }^{32}$. El H-511, más conocido como the racetrack por la conformación de su frente que imitaba la estructura de un hipódromo, fue realizado en baquelita de diversos colores, blanca, verde y marrón, donde destacaba poderosamente la espina central en dorado (Figura 8). El dial desarrollaba sus números sobre las curvas de los extremos, quedando ubicados los botones de sintonía y volumen sobre la moldura resaltada que le daba su peculiar forma. Este modelo

${ }^{31}$ La patente para el receptor de radio tiene el número 113.004 y fue presentada el 18 de noviembre de 1938 y autorizada el 24 de enero de 1939. El desarrollo técnico fue presentado a la oficina de patentes el 3 de julio de 1939 y aprobado finalmente el 12 de enero de 1943 con el número de patente 2.307.807. La documentación se custodia en la Oficina de Patentes de Estados Unidos.

${ }^{32}$ MoMA, 1949. 
de sobremesa eliminaba el asa y reforzaba su estructura con unas patas triangulares que le daban un estilizado aspecto. Este nuevo aparato presentaba notables semejanzas con el patentado unos años antes, en 1946, por los también diseñadores Robert Cooper Scull y Jacques Martial. Asimismo, se inspiró en el patentado por Clifford E. Gruber para la Belmont Radio Corporation en $1946^{33}$.

Los ejemplos analizados demuestran que la colección Rafael Ortiz es una de las más interesantes extrañezas que se custodian en la ciudad, aunque obviamente solo se han presentado algunos de los principales nombres y modelos. Diseñadores como A. F. Thwaites o Isamu Noguchi, de quienes también conserva interesantes piezas o modelos como la Philco Modelo 37-604 o la Fada Modelo The Temple, y diseñadores aún por descubrir pero de gran interés formal, convierten a esta colección en una de las principales claves de la modernidad en la ciudad.

Fecha de recepción: 27 de octubre de 2019

Fecha de aceptación: 13 de abril de 2020

\section{BIBLIOGRAFÍA}

Bunis/Marty/Sue (1997): Antique radio's. Bradford: Collector books.

Castiglioni, Carlo Livio (2007): "Lo «Studio Castiglioni». Una storia lunga un secolo".http://fondazioneachillecastiglioni.it/wp-content/uploads/2015/05/20072015-uno-studioi-lungo-un-secolo.pdf (18-10-2019).

Cohn, Laura (1979): Wells Coates. Architect and designer 1895-1958. Oxford: Oxford Polytechnic Press.

Forty, Adrian (1995): Objects of desire. Design and society since 1750. Londres: Thames and Hudson.

Hafiz Elgohary, Farouk (1966): Wells Coates, and the position in the beginning of the modern movement in Engalnd. Thesis for Ph.D. Londres: University of London. http://discovery.ucl.ac.uk/1317970/1/309103.pdf (29-9-2019).

Hawes, Robert (1991): Radio Art. Londres: Green Wood Publishing Company.

Hitchcock, Henry-Russell/Bauer, Catherine K. (1937): Modern Architecture in England. Nueva York: Museum of Modern Art.

Johnson, J. Stewart (2000): American modern, 1925-1940: design for a new age. Nueva York: Harry N. Abrams Inc.

Kingsley, Rebecca (ed.) (1999): Bakelite radios. Londres: Grange Books.

Kowenhoven, John A. (1967): The arts in modern american civilization. Nueva York: W. W. Norton Publisher.

${ }_{33}$ El modelo fue presentado en la Oficina de Patentes de los Estados Unidos, donde se conserva, el 6 de diciembre de 1950, quedando patentado con el número 165.507 el 25 de diciembre de 1951. La patente del diseño de Scull y Martial fue presentado el 25 de julio de 1945 y aprobado con el número 144.074 el 5 de marzo de 1946. 
Loewy, Raymond (2002): Never leave well enough alone. Londres/Baltimore: The Johns Hopkins University Press.

Maffei, Nicola P. (2018): Norman Bel Geddes. American Design Visionary. Londres/Nueva York: Bloomsbury Publishing Plc.

Martínez-Montiel, Luis F. (2015): "Baquelitas. Creando el futuro". En: Martínez-Montiel, Luis F./Ortiz Domínguez, Rafael (coms.): Baquelitas creando futuro. Madrid: Museo Nacional de Artes Decorativas/Ministerio de Educación, Cultura y Deporte, pp. 9-29.

Martínez-Montiel, Luis F. (2018): Baquelita Paradise. El material que nos hizo modernos. Sevilla: Los sentidos ediciones.

Meikle, Jeffrey (1979): Twentieth Century Limited: Industrial design in America 1925-1939. Philadelphia: Temple University.

Museum of Modern Art (1937): Modern Architecture in England. Nueva York: MoMA. https://www.moma.org/calendar/exhibitions/2750?installation_image_index $=2$ (18-10-2019).

-(1949): Design show. Christmas 1949. Master checklist and press reléase. Nueva York: MoMA. https://www.moma.org/documents/moma_press-release_325704.pdf (26-4-2019).

Porter, Glenn (2002): "Introduction". En: Loewy, Raymond. Never leave well enough alone. Londres/Baltimore: The Johns Hopkins University Press, pp. 13-25.

Powers, Alan (1996): Obituary: Serge Chermayeff. En: Independent, edición Reino Unido, 14-5-1996. https://www.independent.co.uk/incoming/obituary-sergechermayeff-5616070.html (12-10- 2019).

Rispoli, E. Ramón/Jordana, Ester (2016): "Entre hegemonía y crítica: pensar el diseño como transformación”. En: Deconstruyendo herramientas docentes 2. Barcelona: Centre Universitari de Disseny de Barcelona, pp. 419-433.

Russell, Flinchum (1997): Henry Dreyfuss, industrial designer: The man in the brown suit. Nueva York: Cooper-Hewitt Museum.

Shapiro, Danielle (2016): John Vassos. Industrial design for modern life. Minneapolis: University of Minessota Press.

Silverstone, Roger/Haddon, Leslie (1996): "Design and the domestication of information and communication technologies: technical change and everyday life". En: Mansell, Robin/Silverstone, Roger (eds.): Communication by design: the politics of information and communication technologies. Oxford: Oxford University Press, pp. 44-74.

Szerlip, B. Alexandra (2017): The man who designed the future. Norman Bel Geddes. Londres: Melville House Publishing.

Victoria \& Albert Museum (1977): The wireless show! 130 classic radio receivers1920s to 1950s. Londres: V\&M Museum.

Wilson, Richard G. (1986): The machine age in America, 1918-1941. Nueva York: Harry N. Abrams and Brooklyn Museum. 


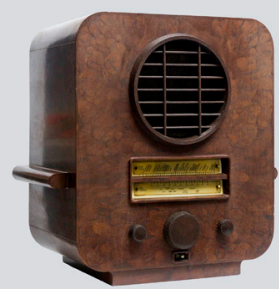

A

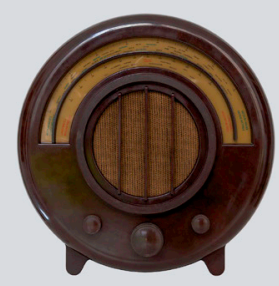

B

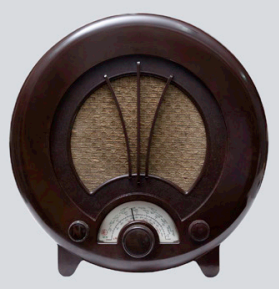

C

Figura 1. A) Serge Chermayeff, EKCO. Modelo AC74, 1933-1934, n inv. 513. B) Wells Coates, EKCO. Modelo AD65, 1932-1934, nº inv. 007.

C) Wells Coates, EKCO. Modelo AD75, 1935, n inv. 008.

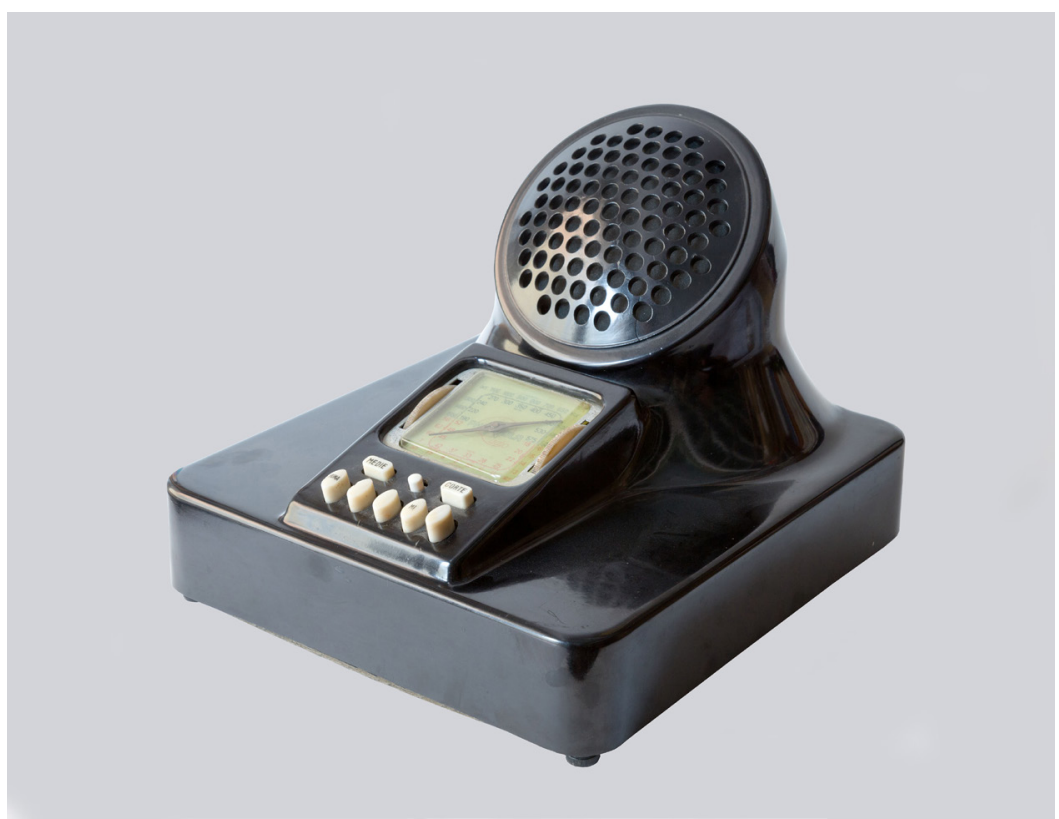

Figura 2. Livio Castiglioni, Pier Castiglioni y Luigi Caccia Dominioni, Radio Phonola. Modelo 547, 1939, $\mathrm{n}^{\circ}$ inv. 001. 


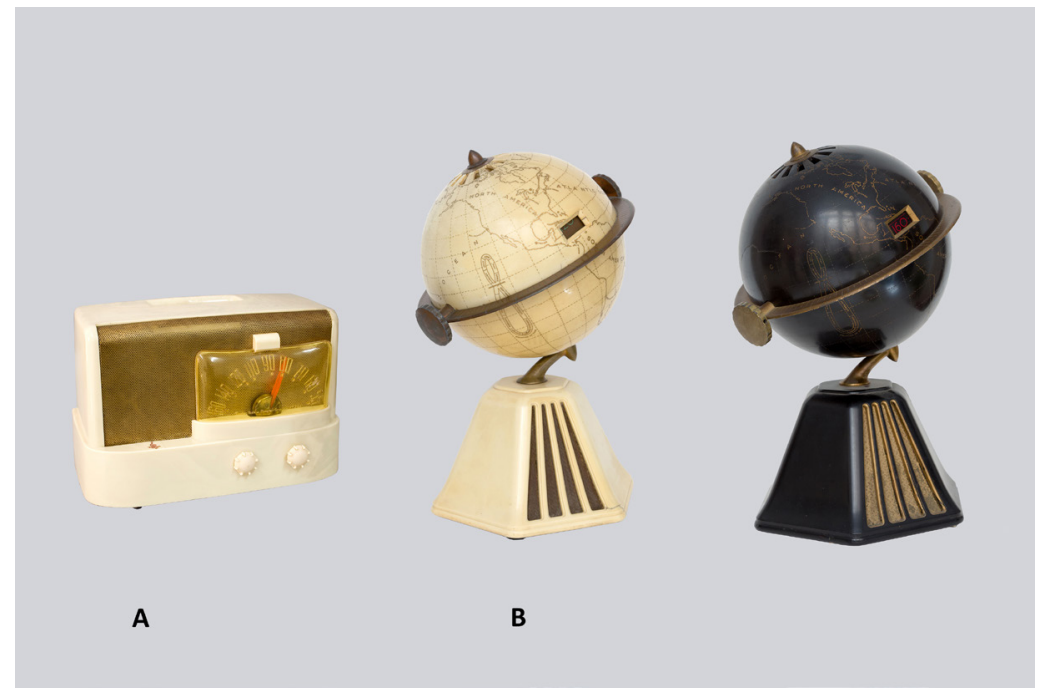

Figura 3. A) Raymond Loewy, Emerson. Radio moderne. Modelo 511, 1947, $\mathrm{n}^{\circ}$ inv. 066. B) Raymond Loewy, Radio Colonial. Modelo 700. New World Globe, $\mathrm{n}^{\circ}$ inv. 004 y 005.

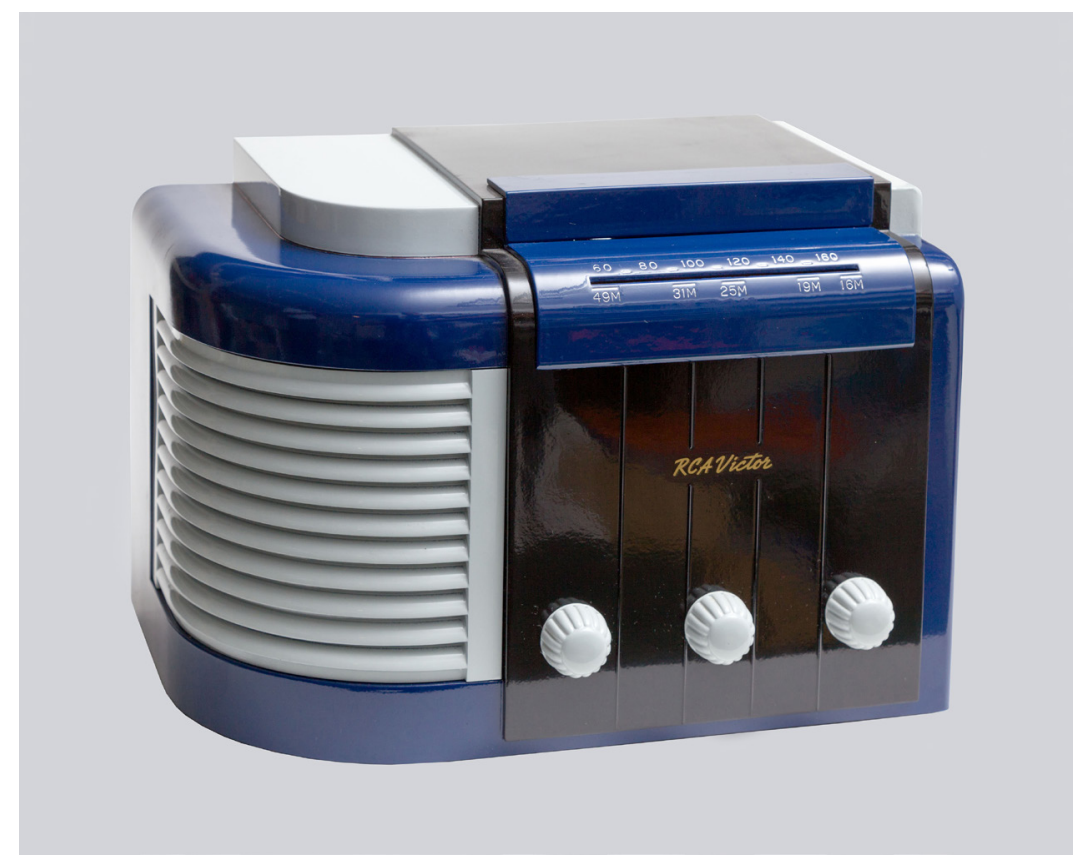

Figura 4. John Vassos, Radio RCA Victor. Modelo 96-X3, 1938, $\mathrm{n}^{\circ}$ inv. 009. 


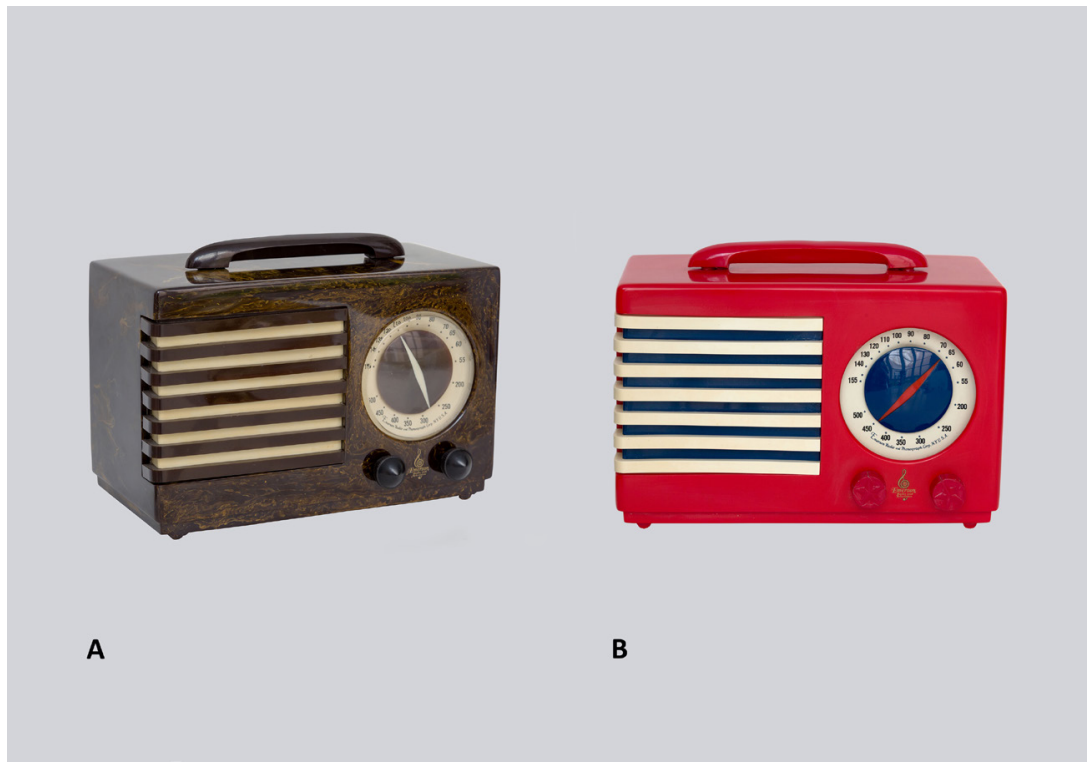

Figura 5. Norman Bel Geddes, A) Emerson. Radio Patriot. B) Emerson Radio Patriot Model Aristocrat, 1939, $\mathrm{n}^{\circ}$ inv. 002 y 003.

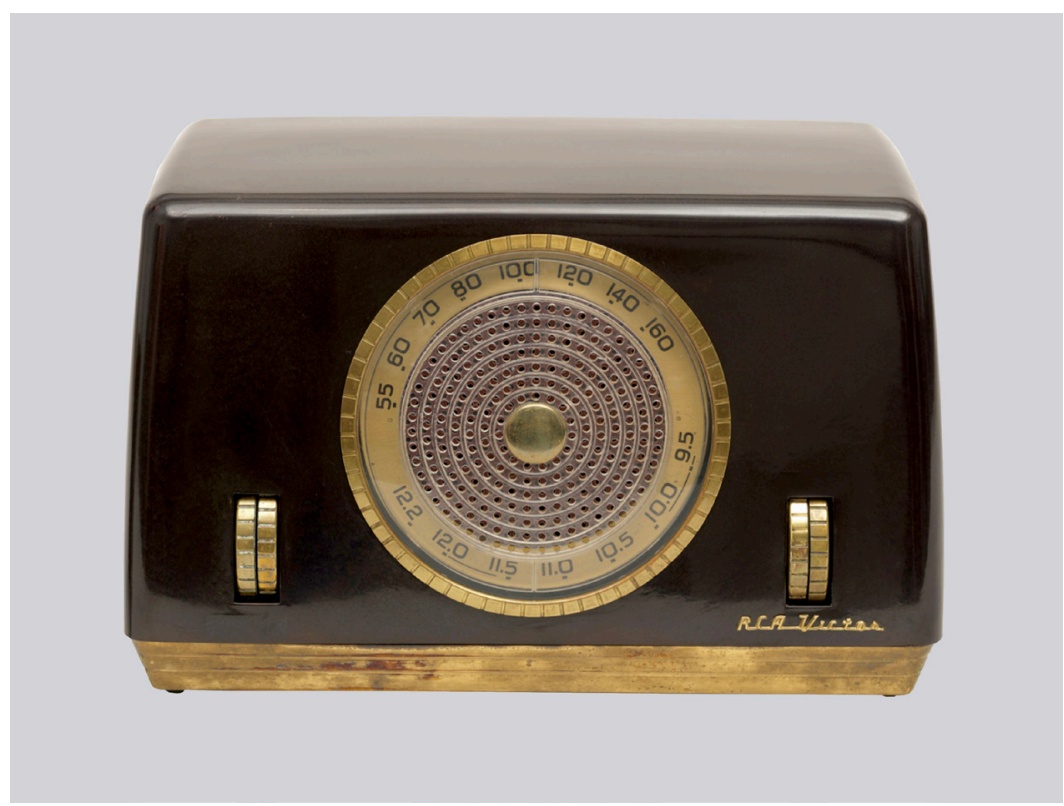

Figura 6. Henry Dreufuss, Radio RCA Victor. Modelo Sunburst $8 X 682,1948, \mathrm{n}^{\circ}$ inv. 545. 


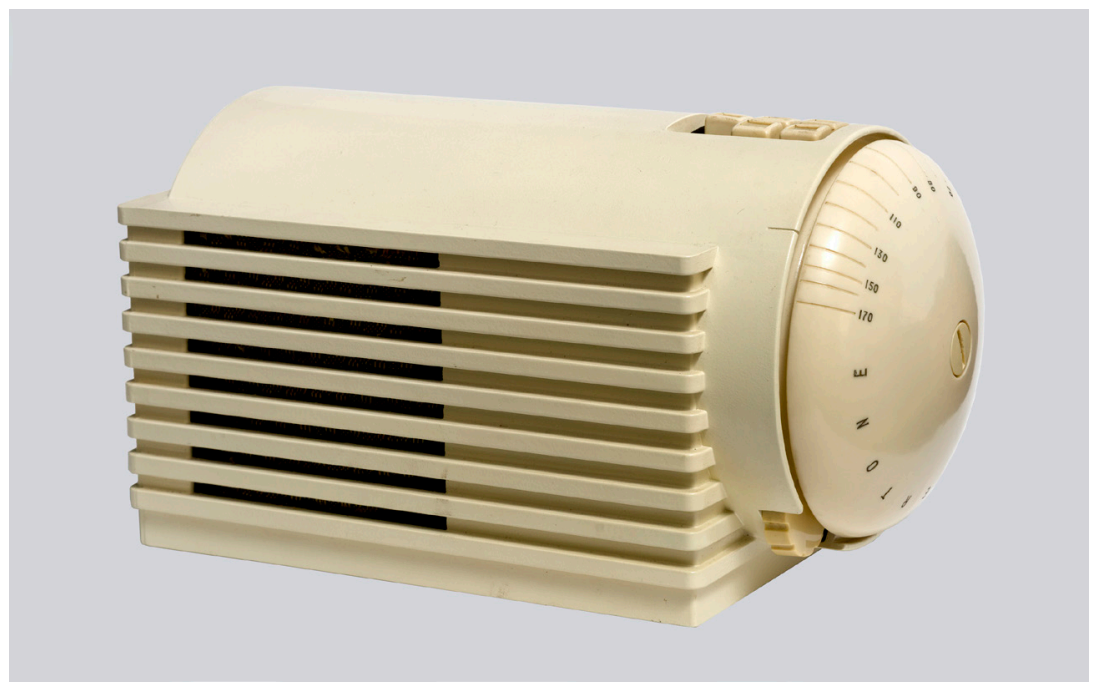

Figura 7. Clarence Karstadt, Radio Silvertone. Modelo 6110 Rocket, 1938.

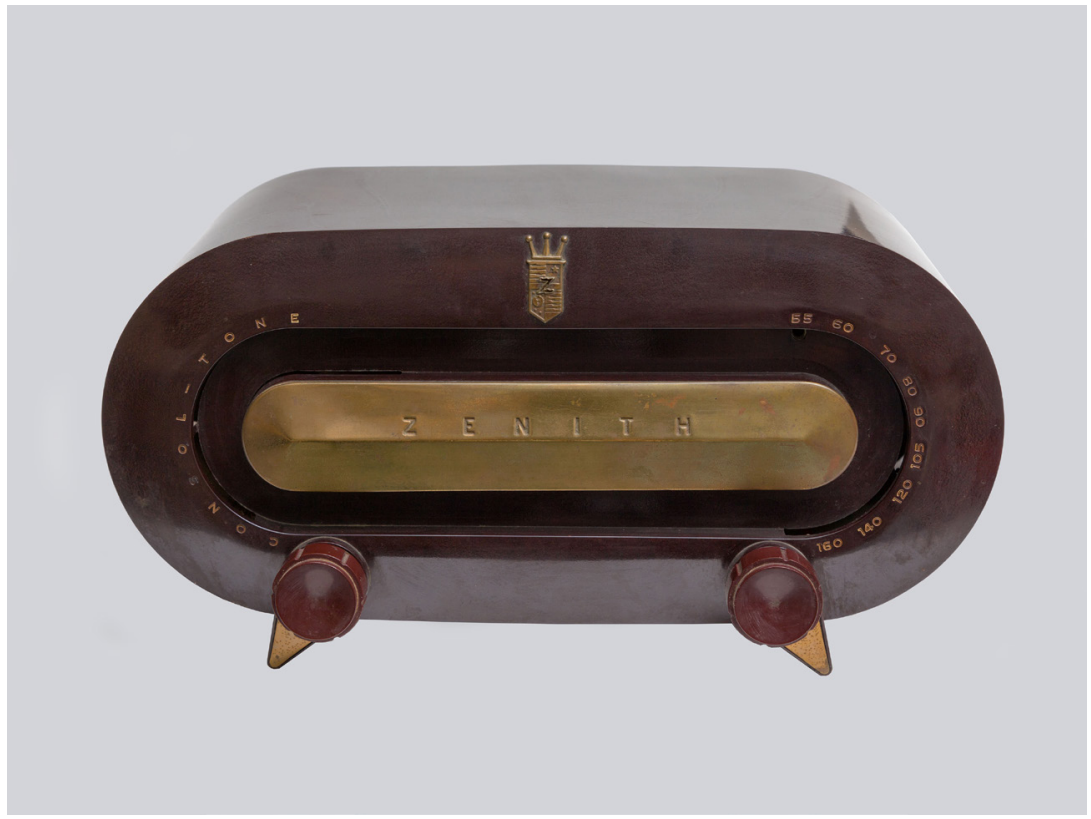

Figura 8. Robert Davol Budlong, Radio Zenith. Modelo H5 11. The racetrack, $1951, \mathrm{n}^{\circ}$ inv. 014. 